\title{
Evaluations of clinical tobacco cessation interventions in Arab populations: a systematic review
}

\author{
Abdallaziz Alzahrane ${ }^{1}$, Robert West ${ }^{1}$, Harveen Kaur Ubhi ${ }^{1}$, Jamie Brown ${ }^{1}$, Nabeel \\ Abdulqader $^{2}$, Osama Samarkandi ${ }^{2}$
}

1. Cancer Research UK Health Behaviour Research Centre, Department of Epidemiology and Public Health, University College London, London, UK.

2. Prince Sultan College for Emergency Medical Services, King Saud University, Saudi Arabia

Conflicts of interest: RW undertakes research and consultancy for companies that develop and manufacture smoking cessation medications. RW is an advisor to the UK's National Centre for Smoking Cessation and Training. JB received a 1-year unrestricted research grant from Pfizer in 2012.

Funding: The authors extend their appreciation to the Deanship of Scientific Research at King Saud University for funding this work through the Research Project No NGF-14-0210. JB is funded by the Society for the Study of Addiction and Cancer Research UK. 


\begin{abstract}
:
Background and Aims: Tobacco smoking is prevalent among Arab smokers. Interventions to support smoking cessation may differ in effectiveness in this population from Western populations usually studied. This review assessed evidence of effectiveness of clinical smoking interventions in Arab smokers.

Methods: A systematic search for comparative trials evaluating tobacco cessation interventions in Arab populations was conducted in the MEDLINE, EMBASE, PyschINFO, CINHAL and Web of Science databases. Behavioural, pharmacological and combined interventions were included. Reference lists of included studies were hand searched. The outcome measure was self- reported tobacco abstinence at the final followup, with biochemical verification where available. Assessment of evidence for effectiveness was undertaken using Bayes Factors.

Results: A total of 659 titles and abstracts were identified. Five studies met the inclusion criteria. Four of these were randomized controlled trials and one was a non-randomized comparative trial. Differences between study features precluded meaningful aggregation for a meta-analysis. The four randomized trials all yielded Bayes Factors less than 1, suggesting no effect of the intervention compared with the control condition. The nonrandomized trial, conducted in tuberculosis clinics in Sudan, yielded an extremely high Bayes Factor (>1000), supporting the hypothesis of effectiveness; however, the study was judged to have a high risk of bias.
\end{abstract}

Conclusions: As yet, there is no convincing direct evidence that clinical smoking cessation interventions, which are found to be effective in Western populations, are also effective for Arab smokers. There is an urgent need for high quality randomized trials evaluating interventions in this population.

Key words: tobacco, cessation, intervention, effectiveness, systematic review, Bayes Factor. Arab. 


\section{Introduction}

Smoking tobacco is one of the most important preventable causes of morbidity and premature death in the world (1). Smoking cessation interventions have been shown to be highly cost-effective both in Western countries and some low and middle income countries (2). However, cultural and contextual factors may be an important factor in determining effectiveness of different types of intervention and to date there have been no published reviews of evaluations of effectiveness of smoking cessation interventions in Arab smokers. The present study addressed this gap in the literature.

Arab populations have different patterns of tobacco use from many Western populations. For example, they have a much higher prevalence of male than female smoking (3). Also, the smoking of water-pipes is common (4). What little research there is suggests that there is widespread acknowledgement that smoking is harmful to health but low self-efficacy with regard to quitting (5). Despite efforts to implement smoking cessation interventions in Arab smokers, an informal analysis of the literature suggests that little research has been conducted. There are surveys and observational studies of Arab smokers, many of them in Western countries (6-17), but it is not clear what the evidence base is for interventions.

Jordan has recently published the first tobacco cessation guidelines in an Arab country (4). Oman has set out a case for more action to combat tobacco use (13). The recommendations are based largely on studies carried out in the West. It is important to have as much information as possible on interventions that have been evaluated in the cultural context in which they will be implemented.

When singling out any particular population for study, it is important to consider whether there are any reasons why this population should be different from those that have already been studied. Arab smokers represent a clearly demarcated cultural group. While there is clearly heterogeneity within the population, there is typically a strong religious identity and adherence to the Islamic faith. There are cultural mores around the roles of particular sections of society, and precepts relating to use of psychoactive drugs including alcohol. It may be, therefore, that interventions that have been found to be effective in Western cultures may be less, or more, effective in this population; and interventions that would not be effective in Western smokers may prove effective.

Evaluations of intervention effectiveness ideally would have random allocation of participants to intervention versus control conditions but under certain circumstances nonrandomized comparative studies can be informative. Therefore this review included RCTs and non-randomised comparative studies.

When assessing outcomes in smoking cessation studies, one generally wants there to be follow up for 6 months or more from the target quit date to have a reasonable degree of confidence that any intervention effects will be preserved for long enough to have a health impact (18). However, shorter term studies can also be informative. For example, failure to find an effect on short-term outcomes means it is extremely unlikely that an effect will be found longer term. The present review included all studies regardless of duration of 
follow-up, and, following the lead of Cochrane reviews of this kind, used data from the longest follow point in each study.

Biochemical verification of abstinence is recommended in clinical smoking cessation trials because of social pressure on participants to report being abstinent (18). However, studies in minimally resourced countries may not be able to achieve this and so this review included studies that relied on self-reported abstinence but recorded whether there was also biochemical verification.

When evaluating behaviour change interventions, it is important to be able to characterize these in a way that is consistent across studies. The opportunity to achieve this has recently been enhanced by development of a taxonomy of intervention components known as 'behaviour change techniques' (BCTs) (19). A BCT taxonomy has been specifically developed for clinical smoking cessation interventions (20). We therefore used this classification to describe the interventions being evaluated in this review.

To our knowledge, this is the first published systematic review of evaluations of clinical effectiveness of smoking cessation interventions in Arab smokers. Besides this, its novel features are: BCT coding to specify intervention content, and use of Bayes Factors to test hypotheses of intervention effectiveness. The research questions addressed in this review were:

1- Is there evidence from comparative studies to be confident that clinical smoking cessation interventions found to be effective in Western populations are also effective in Arab smokers?

2- What is the content of interventions tested?

\section{Methods}

\section{Search Strategy}

The review followed the PRISMA guidelines (21) (see Supplementary File Table S4 for PRISMA checklist). A systematic search of the MEDLINE, EMBASE, PyschINFO, CINHAL and Web of Science databases was conducted using the following search terms (Supplementary File Table S3): ((smoking or tobacco or nicotine or cigarettes or shisha or water-pipe or smokeless tobacco)) adj5 (cessation or control or discontinue\$ or abstinence or quit)), OR smoking cessation OR tobacco combined with (Arab* or Syria or United Arab Emirates or Saudi Arabia or Kuwait or Qatar or Oman or Bahrain or Iraq or Jordan or Lebanon or Egypt or Algeria or Comoros or Djibouti or Libya or Mauritania or Morocco or Somalia or Sudan or Tunisia or Yemen or Palestine). The search terms and subject headings were adjusted according to differences in the databases.

The Saudi Digital Library was also accessed to search for grey literature in the Arabic language. Authors were contacted to provide original documents where necessary. No limits were applied for language in the original search, but only English and Arabic language papers were included in the review. No explicit limitations were applied with regard to publication dates. The search was carried at the end of 2017 and then checked in 
July 2018. Abstracts of articles were reviewed against our inclusion and exclusion criteria. The references cited by included studies were reviewed for additional relevant cited articles, and the citation search facility was employed to identify further potentially relevant original studies and if in doubt the full-text was used.

\section{Inclusion and exclusion criteria}

The inclusion criteria were:

- Smoking cessation interventions of all kind of tobacco products (e.g., cigarettes, shisha, water-pipe, and smokeless tobacco).

- Report of abstinence or quit rate at the final follow-up.

- Comparative trials conducted among Arab smokers resident anywhere in the world.

- English and Arabic language papers only.

The exclusion criteria were:

- Studies of smoking prevention and reduction in cigarette consumption.

\section{Data extraction}

Details of studies were tabulated providing information on data abstraction. The two reviewers extracted the data independently, and then arrived at a consensus. Data extracted were: author/year, country-setting, follow-up period, sample size, intervention, outcome measure, reported results and quality (Jadad score (22)).

\section{BCT analysis}

A taxonomy of BCTs for behavioural support for smoking cessation was used to characterize the content of the behavioural interventions (20) (Supplementary file Table S2). The taxonomy has four high-level categories:

1. Addressing motivation directly - increasing motivation to stop and decreasing motivation to smoke

2. Maximizing self-regulatory skills - avoiding and coping with smoking triggers

3. Supporting adjuvant activities - promoting effective use of stop smoking medicines and other activities that may aid cessation

4. Other supporting BCTs - promoting engagement with the intervention, tailoring and gathering information

Intervention and control conditions of included studies were characterized using this taxonomy, and the results tabulated in terms of numbers of studies using each one.

Quality assessment 
Two reviewers (AA and HKU) independently assessed the included studies for quality. RCTs were assessed using the Jadad scale, which is based on randomization, blinding and descriptions of dropouts and withdrawals from studies (22).

\section{Data synthesis}

A Bayesian approach was used to test for the relative likelihood of the hypothesis (H1) of an effect size odds ratio of between 1 and 2 with a uniform distribution (i.e. no assumption as to where in the range the effect lay between no-effect and an odds ratio of 2) versus the null hypothesis $(\mathrm{H} 0)$ of an odds ratio of 1. Bayes Factors (BF), the ratio of likelihood of the study hypotheses (H1) over the null hypotheses (H0) were calculated. A BF value greater than 1 is supportive of $\mathrm{H} 1$ relative to $\mathrm{H} 0$, whereas a $\mathrm{BF}$ less than 1 is supportive of $\mathrm{H} 0$. A BF value over 3 or less than $1 / 3$ indicates substantial support for $\mathrm{H} 1$ or $\mathrm{H} 0$ respectively (23).

The authors collectively made a judgement as to whether the studies were sufficiently similar to warrant aggregation of BFs. This was based on judgements about similarity of intervention type, outcome measure, study design and context.

\section{Results}

The initial search generated 1,825 papers (Figure 1). There were 659 papers identified after the removal of duplicate studies. These papers were screened based on titles and abstracts, leaving 62 papers to be screened using full-text against inclusion criteria. Based on the inclusion and exclusion criteria, five papers were included in the final review. Of the papers excluded, two were written in French; six were excluded due to being either reduction/initiation or prevention studies, 44 were not relevant based on reading the fulltext of titles and abstract and five studies were excluded because there was no comparison group (See Supplementary File Table S1).

Table 1 shows the characteristics of the included studies. Four of the included studies were RCTs. One study was a non-randomized comparative study. Follow up varied from 2 to 12 months. Of the four RCTs, three were conducted in Syria and one among Arab smokers in Australia. Table 2 shows the main findings. Table 3 shows the BCTs included in the intervention and control conditions.

One RCT (24) included smokers in Syria who had smoked one or more cigarettes per day in the previous year and were motivated to quit smoking. Fifty participants took part in either the brief or intensive behavioural support groups. As the brief intervention was conducted in only one session, all participants received the full intervention. However, the intensive intervention group included four sessions and only $10 \%$ of participants received all sessions, $60 \%$ received three sessions and $76 \%$ received two sessions. A 3-month assessment of confirmed seven-day point prevalent carbon monoxide (CO) was $16 \%$ (4 of 25) and 4\% (1 of 25) for the brief and intensive groups respectively. The continuous abstinence rate was $8 \%$ ( 2 of 25) and 4\% (1 of 25) of smokers for the brief and intensive groups respectively. The intervention condition received relatively little by way of 
additional BCTs over and above what was in the control condition: prompting commitment (BM6), and barrier identification and problem solving (BS1) (Table 3).

An RCT of culturally tailored telephone support (25) was conducted in Sydney, Australia, for Arab smokers recruited from among patients visiting their primary health care physician. Two Arabic- speaking psychologists provided the telephone support; one male and one female. There were 213 smokers randomized to the intervention and 194 to the control condition. Of the 213 intervention participants, 101 consented to receive telephone support. The number lost during follow-up in smokers who were allocated to receive usual care in the control group was $21 \%$ at 6 months and 34\% at 12 months. In the intervention group, this number was $24 \%$ at 6 months and $44 \%$ at 12 months. The point prevalence abstinence rates at 6 months, calculated by intention-to- treat, were $11.7 \%(n=25)$ and $12.9 \%(\mathrm{n}=25)$ for the intervention and control groups respectively. At 12 months, they were $8.4 \%(\mathrm{n}=18)$ and $11.3 \%(\mathrm{n}=22)$ respectively. The intervention content contained a range of different BCTs that were not included in the control condition, covering motivational and self-regulatory aspects (Table 3).

There was one study (26) conducted among Syrian adults who smoked only water pipes three or more times a week. The three-month follow-up assessment found that the group who received a brief intervention had continuous abstinence rates of $17.4 \%$ compared with $18.5 \%$ in the intervention group. In terms of BCTs the intervention only included one additional component: barrier identification and problem solving (BS1).

There was one trial of a pharmacological treatment conducted in Syria involving $(21,14$ and $7 \mathrm{mg}$ nicotine patches versus placebo) in the context of a behavioural support programme with visits at 2 week intervals (27). It recruited 269 smokers who had smoked five or more cigarettes per day for more than a year. The prolonged abstinence rates for the placebo and nicotine patches groups were $20 \%$ and $21.6 \%$ at the end of treatment, $14.1 \%$ and $13.4 \%$ at six months and $11.9 \%$ and $12.7 \%$ at 12 months respectively.

The only non-randomized comparative study was conducted in Sudan (28) among tuberculosis (TB) patients using tobacco products. Two medical assistants each from 24 districts delivered the intervention. Included cases were previously untreated male patients. Follow-up surveys were administered 12 months from the first enrolment. There were 308 participant smokers in the intervention group, 53.6\% of whom reported having quit at follow-up. There were 42 participants in the control group, 14.3\% of whom reported quitting. It is not known what BCTs were included in the control condition but in the intervention condition, the focus was on assessing smoking behaviour (RI1) and readiness to quit (RI2).

Table 3 shows that the Bayes Factors for the four RCTs were all less than 1 and in two cases less than $1 / 3$, indicating substantial evidence for the null hypothesis. The nonrandomized study, by contrast, had a very high Bayes Factor, strongly supporting the hypothesis of an effect.

From the published reports the interventions contained few more BCTs than the control conditions (Table 3). 


\section{Discussion}

None of the four RCTs showed evidence of intervention effectiveness. In two studies there was substantial support for the null hypothesis. The one non-randomized study showed a very large intervention effect but had a high risk of bias. From the published reports, the intervention conditions appeared to contain few behaviour change techniques (BCTs) over and above those in the control conditions.

The shortage of high quality evaluations of smoking cessation interventions in Arab smokers may be due to a number of factors. It may reflect a low priority given to smoking research in Arab countries, a lack of expertise, or limited research infrastructure. Given the importance of smoking as a public health hazard, this is an issue that requires urgent attention and programmes put in place to remedy it.

The findings that intervention conditions did not appear to have much added content in terms of BCTs than control conditions is important when interpreting these findings. It is possible that multi-component interventions that follow the evidence base in Western studies (20) may have an effect in this population. However, it is also possible that there are other BCTs that may play an important role: for example, ones that work with specific cultural and religious principles.

When designing intervention evaluations for this population in future it will be important to maximize the quality of those studies by adopting some key principles of design and reporting (29): pre-registration of clinical trials, hypotheses and analysis plans (30), ensuring adequate power to detect realistic effect sizes, full specification and justification of components of the intervention and control conditions, full use of relevant CONSORT guidelines including the extension for social and psychological interventions (31), and use of the Russell Standard or similarly rigorous criteria for outcome assessment (18).

This review had a number of limitations. Studies were not considered if they were reported in languages other than Arabic or English. Characterising the content of interventions in terms of BCTs was based on the published study report and not all the BCTs may have been included. The literature itself was sparse and so confident conclusions about effectiveness of particular interventions could not be drawn.

When considering what interventions to test in future RCTs, there are a number of considerations. Clearly, it makes sense to test interventions that have the highest likelihood of success. In that regard, varenicline and cytisine seem the obvious choices. Varenicline has been found to have the largest effect of all the medications, is easy to administer and has been found to be effective in a wide range of cultures (32). Cytisine has much less direct evidence but a similar mechanism of action (32). In terms of behavioural support, multi-session behavioural support based on what is offered in the UK stop-smoking services has a strong track-record and this kind of approach has proved effective in other countries (2). It is not clear, however, whether the medication or behavioural support options would be acceptable to Arab smokers. Research is needed to assess this, and to examine the acceptability of other kinds of intervention such as psychological support delivered through mobile digital devices (33). 
In conclusion, there is an urgent need to conduct high quality RCTs of smoking cessation intervention for Arab smokers. As part of the development process it will be important to evaluate the cultural factors that may be harnessed to promote smoking cessation and the acceptability of different types of intervention to the target population. 
Table 1: Characteristics of the included studies

\begin{tabular}{|c|c|c|c|c|c|c|}
\hline Study & $\begin{array}{c}\text { Follow-up } \\
\text { period }\end{array}$ & $\begin{array}{c}\text { Country } \\
\text { setting }\end{array}$ & Sample size & Outcome measure & Reported results & $\begin{array}{c}\text { Quality } \\
\text { (Jadad score) }\end{array}$ \\
\hline El Sony (2007) & $\begin{array}{l}\text { From } 22 \\
\text { July to } 30 \\
\text { November } \\
2002\end{array}$ & Sudan & $\begin{array}{l}513 \text { TB patients } \\
\text { of which } 350 \text { were } \\
\text { current tobacco users }\end{array}$ & $\begin{array}{l}\text { Tobacco use rates at intervention centers at the } \\
\text { beginning of treatment and at } 12 \text { months. }\end{array}$ & $\begin{array}{l}53.6 \% \text { of } 308 \text { patients in the intervention group quit and } \\
14.3 \text { of the } 42 \text { patients in the control group quit. }\end{array}$ & n/a \\
\hline $\begin{array}{l}\text { Asfar, T. et al } \\
\text { (2008). }\end{array}$ & N/A & Syria & $\begin{array}{l}50(92 \% \text { male in } \\
\text { intervention and } 80 \% \text { in } \\
\text { control) }\end{array}$ & $\begin{array}{l}\text { 1. A 7-day point prevalent abstinence rate at } 3 \\
\text { months, confirmed biochemically by a CO test } \\
\text { 2.A continuous abstinence rate confirmed by a } \\
\text { CO test }\end{array}$ & $\begin{array}{l}\text { At } 3 \mathrm{M}: 7 \text {-day point prevalent: } \mathrm{N} \text { brief }=4 \text { of } 25(16 \%), \mathrm{N} \\
\text { intensive }=1 \\
\text { of } 25(4 \%) \text {, continuous: } \mathrm{N} \\
\text { brief }=2 \text { of } 25(8 \%), \mathrm{N} \\
\text { Intensive }=1 \text { of } 25(4 \%)\end{array}$ & 3 \\
\hline $\begin{array}{l}\text { Girgis et al. } \\
\text { (2011). }\end{array}$ & $\begin{array}{l}\text { April } 2005 \\
\text { to March } \\
2006\end{array}$ & Australia & $\begin{array}{l}407(45.1 \% \text { male in } \\
\text { intervention and } 52.1 \% \text { in } \\
\text { control) }\end{array}$ & $\begin{array}{l}\text { 1. Point prevalence abstinence rate at } 6 \text { and } 12 \\
\text { months } \\
\text { 2. Stage-of- change towards intention to quit } \\
\text { at } 6 \text { and } 12 \text { months }\end{array}$ & $\begin{array}{l}\text { At } 6 \mathrm{M}: \mathrm{N} \text { intervention }=25 \text { of } 213(11.7 \%), \mathrm{N} \\
\text { control }=23 \text { of } 194 \\
(12.9 \%) \mathrm{CI}=0.97(0.7- \\
1.3) \\
\text { At } 12 \mathrm{M}: \mathrm{N} \text { intervention }=18 \text { of } 213(8.4 \%), \mathrm{N} \\
\text { control }=22 \text { of } 194 \\
(11.3 \%) \mathrm{CI}=0.93(0.6- \\
1.3)\end{array}$ & 3 \\
\hline $\begin{array}{l}\text { Ward, K. et al } \\
\text { (2013). }\end{array}$ & $\begin{array}{l}\text { June } 2007 \\
\text { to April } \\
2008\end{array}$ & Syria & $\begin{array}{l}269(75.4 \% \text { male in } \\
\text { intervention \& } 81.5 \% \text { in } \\
\text { placebo })\end{array}$ & $\begin{array}{l}\text { A prolonged abstinence at the end of treatment ( } 46 \\
\text { days of post- quit), and } 12 \text { months of smoking } \\
\text { cessation }\end{array}$ & $\begin{array}{l}\text { At EOT: prolonged: placebo }(20 \%), \text { nicotine } \\
(21.6 \%), 7 \text { day: placebo } \\
(25.9 \%), \text { nicotine } \\
(25.4 \%) \text {. At } 6 \mathrm{M}: \\
\text { prolonged: placebo }(14.1 \%), \text { nicotine } \\
(13.4 \%), 7 \text { day: placebo } \\
(19.3 \%), \text { nicotine }(14.2 \%) \text { At } 12 \mathrm{M} \text { : prolonged: placebo } \\
(11.9 \%) \text {, nicotine } \\
(12.7 \%), 7 \text { day: placebo } \\
(14.8 \%), \text { nicotine }(20.1 \%)\end{array}$ & 5 \\
\hline $\begin{array}{l}\text { Asfar, T. et al } \\
(2014)\end{array}$ & $\begin{array}{l}\text { November } \\
2007 \\
\text { to October } \\
2008\end{array}$ & Syria & $\begin{array}{l}50(95.7 \% \text { male in brief } \\
\text { intervention \& intensive } \\
\text { intervention) }\end{array}$ & $\begin{array}{l}\text { 1. Long-term abstinence at } 3 \text { months post quit-date } \\
\text { 2.Prevalence of abstinence at } \\
\text { 7-day point with adherence to treatment }\end{array}$ & $\begin{array}{l}\text { At 3M: } 7 \text {-day point prevalent: } \mathrm{N} \text { brief }=7 \text { of } 23(30.4 \%), \\
\mathrm{N} \text { intensive }= \\
11 \text { of } 27(40.7 \%), \\
\text { prolonged: } \mathrm{N} \text { brief }=7 \text { of } 23(30.4 \%), \mathrm{N} \text { intensive }= \\
12 \text { of } 27(44.4 \%), \\
\text { continuous: } \mathrm{N} \text { brief }=4 \text { of } 23(17.4 \%), \mathrm{N} \text { intensive }= \\
5 \text { of } 27(18.5 \%)\end{array}$ & 3 \\
\hline
\end{tabular}




\section{Table2: Findings from included studies}

\begin{tabular}{|c|c|c|c|c|c|c|c|c|c|c|c|}
\hline Study & $\begin{array}{c}\text { Stopped } \\
\text { smoking } \\
\text { (intervention } \\
\text { group) }\end{array}$ & $\begin{array}{c}\text { Continue to } \\
\text { smoke } \\
\text { (intervention } \\
\text { group) }\end{array}$ & $\begin{array}{l}\text { Stopped } \\
\text { smoking } \\
\text { (control) }\end{array}$ & $\begin{array}{c}\text { Continue to } \\
\text { smoke } \\
\text { (control) }\end{array}$ & Total & $\begin{array}{l}\text { Duration of } \\
\text { follow- up }\end{array}$ & $\begin{array}{c}\text { Bayes } \\
\text { Factor }^{\wedge}\end{array}$ & OR & Log odds & SE log odds & $95 \%$ CI \\
\hline $\begin{array}{l}\text { *ELSO } \\
\text { NY et al, } 2007\end{array}$ & 165 & 143 & 6 & 36 & 350 & $\begin{array}{c}12 \\
\text { months }\end{array}$ & 2149 & 6.92 & 1.93 & 0.46 & 2.84 to 16.90 \\
\hline \begin{tabular}{|l|} 
ASFAR \\
et al, 2008
\end{tabular} & 1 & 24 & 2 & 23 & 50 & $\begin{array}{c}3 \\
\text { months }\end{array}$ & 0.49 & 0.48 & -0.74 & 1.26 & 0.04 to 5.65 \\
\hline \begin{tabular}{|l} 
GIRGIS \\
et al, 2011
\end{tabular} & 18 & 195 & 22 & 172 & 407 & $\begin{array}{c}12 \\
\text { months }\end{array}$ & 0.11 & 0.72 & -0.33 & 0.33 & 0.37 to 1.39 \\
\hline $\begin{array}{l}\text { WARD } \\
\text { et al, } 2013\end{array}$ & 17 & 117 & 16 & 119 & 269 & $\begin{array}{c}12 \\
\text { months }\end{array}$ & 0.27 & 0.93 & -0.07 & 0.37 & 0.45 to 1.92 \\
\hline \begin{tabular}{|l|} 
ASFAR \\
et al, 2014
\end{tabular} & 5 & 22 & 4 & 19 & 50 & $\begin{array}{c}3 \\
\text { months }\end{array}$ & 0.50 & 1.08 & 0.08 & 0.74 & 0.25 to 4.61 \\
\hline
\end{tabular}

$\wedge$ Bayes Factor (experimental hypothesis=uniform distribution of $\log$ odds between 0 and 2, null hypothesis=log odds of 0 ; < 1/3 ineffective; $1 / 3$ to 3 insensitive; $>3$ effective; $*$ The number of quitters was estimated based on provided percentages 
Table 3: Behaviour change techniques (BCTs) used in the intervention and control conditions

\begin{tabular}{|l|l|l|}
\hline \multicolumn{1}{|c|}{ Study } & \multicolumn{1}{|c|}{ Intervention condition } & \multicolumn{1}{|c|}{ Control condition } \\
\hline ELSONY et al, 2007 (15) & RI1, RI2 & Unknown \\
\hline ASFAR et al, 2008 (17) & $\begin{array}{l}\text { Control condition plus BS1, } \\
\text { BM6 }\end{array}$ & BM11, BM1, BS4, BS2, BS8, BM4, A2, RC5 \\
\hline GIRGIS et al, 2011 (16) & RC5, RI1, RI2, RI3, BS2, BS4, A5, A1, BM3 & RC5 \\
\hline WARD et al, 2013 (18) & Same as control condition plus nicotine transdermal patch & $\begin{array}{l}\text { A1,A2, BM2,BM11, BS1, BS3, R11, R12, } \\
\text { R13, R14 BCTs plus placebo nicotine patch }\end{array}$ \\
\hline ASFAR et al, 2014 (12) & Control condition plus BS1 & $\begin{array}{l}\text { BM1, BM3, BS2, BS4, BS8, BM4, A2, } \\
\text { BM6, BM11, RC5, R11, R12 }\end{array}$ \\
\hline
\end{tabular}

Note: See Supplementary Table S2 for descriptions of BCTs 
Figure1: The PRISMA flow diagram

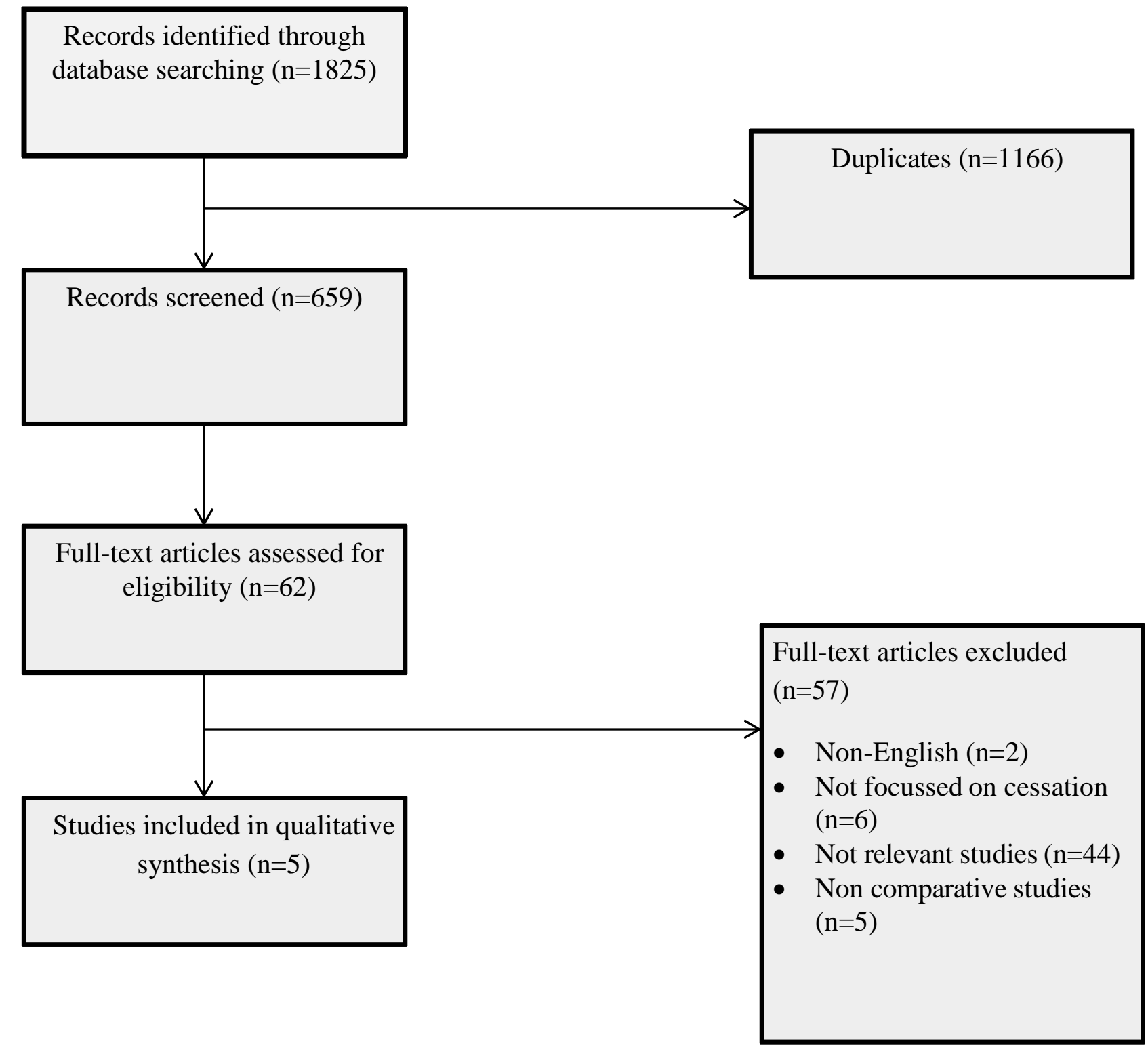




\section{References}

1. Peacock A, Leung J, Larney S, Colledge S, Hickman M, Rehm J, et al. Global statistics on alcohol, tobacco and illicit drug use: 2017 status report. Addiction. 2018.

2. West R, Raw M, McNeill A, Stead L, Aveyard P, Bitton J, et al. Health-care interventions to promote and assist tobacco cessation: a review of efficacy, effectiveness and affordability for use in national guideline development. Addiction. 2015;110(9):1388-403. 3. Gowing LR, Ali RL, Allsop S, Marsden J, Turf EE, West R, et al. Global statistics on addictive behaviours: 2014 status report. Addiction. 2015;110(6):904-19.

4. Ayub H, Obeidat N, Leischow S, Glynn T, Hawari F. Jordan tobacco dependence treatment guidelines: rationale and development. Eastern Mediterranean health journal $=$ La revue de sante de la Mediterranee orientale = al-Majallah al-sihhiyah li-sharq al-mutawassit. 2016;21(11):844-50.

5. Eggert J, Al-Delaimy WK. Behaviours and attitudes related to smoking among a Bedouin population in rural Jordan. Eastern Mediterranean health journal $=\mathrm{La}$ revue de sante de la Mediterranee orientale = al-Majallah al-sihhiyah li-sharq al-mutawassit. 2013;19(6):513-9.

6. Haddad L, Corcoran J. C ulturally Tailored Smoking Cessation for Arab American Male Smokers in Community Settings: A Pilot Study. Tobacco Use Insights. 2013(6).

7. Rice VH, Templin T, Kulwicki A. Arab-American adolescent tobacco use: Four pilot studies. Preventive medicine. 2003;37(5):492-8.

8. Ghadban R, Haddad L, Thacker LR, 2nd, An K, Balster RL, Salyer J. Smoking Behaviors in Arab Americans: Acculturation and Health Beliefs. Journal of transcultural nursing : official journal of the Transcultural Nursing Society. 2018:1043659618783235.

9. Al-Houqani M, Leinberger-Jabari A, Al Naeemi A, Al Junaibi A, Al Zaabi E, Oumeziane $\mathrm{N}$, et al. Patterns of tobacco use in the United Arab Emirates Healthy Future (UAEHFS) pilot study. PloS one. 2018;13(5):e0198119.

10. Al-Rawi NH, Alnuaimi AS, Uthman AT. Shisha Smoking Habit among Dental School Students in the United Arab Emirates: Enabling Factors and Barriers. International journal of dentistry. 2018;2018:2805103.

11. Heydari G, Zaatari G, Al-Lawati JA, El-Awa F, Fouad H. MPOWER, needs and challenges: trends in the implementation of the WHO FCTC in the Eastern Mediterranean Region. Eastern Mediterranean health journal $=$ La revue de sante de la Mediterranee orientale = al-Majallah al-sihhiyah li-sharq al-mutawassit. 2018;24(1):63-71.

12. Idris A, Al Saadi T, Turk T, Alkhatib M, Zakaria M, Sawaf B, et al. Smoking behaviour and patterns among university students during the Syrian crisis. Eastern Mediterranean health journal $=$ La revue de sante de la Mediterranee orientale $=$ al-Majallah al-sihhiyah li-sharq almutawassit. 2018;24(2):154-60.

13. Al-Lawati J, Mabry RM, Al-Busaidi ZQ. Tobacco Control in Oman: It's Time to Get Serious! Oman medical journal. 2017;32(1):3-14.

14. Daou KN, Bou-Orm IR, Adib SM. Factors associated with waterpipe tobacco smoking among Lebanese women. Women \& health. 2017:1-11.

15. Hamadeh RR, Ahmed J, Al Kawari M, Bucheeri S. Smoking behavior of males attending the quit tobacco clinics in Bahrain and their knowledge on tobacco smoking health hazards. BMC public health. 2018;18(1):199.

16. Osman A, Daoud N, Thrasher JF, Bell BA, Walsemann KM. Ethnic Discrimination and Smoking-Related Outcomes among Former and Current Arab Male Smokers in Israel: The Buffering Effects of Social Support. Journal of immigrant and minority health. 2017.

17. Salloum RG, Abu-Rmeileh N, Hamadeh R, Thomas J, Mostafa A, Yusufali A, et al. Policy-Relevant Context of Waterpipe Tobacco Smoking among University Students in Six Countries Across the Eastern Mediterranean Region: A Qualitative Study. Asian Pacific journal of cancer prevention : APJCP. 2017;18(9):2533-40. 
18. West R, Hajek P, Stead L, Stapleton J. Outcome criteria in smoking cessation trials: proposal for a common standard. Addiction. 2005;100(3):299-303.

19. Michie S, Richardson M, Johnston M, Abraham C, Francis J, Hardeman W, et al. The behavior change technique taxonomy (v1) of 93 hierarchically clustered techniques: building an international consensus for the reporting of behavior change interventions. Annals of behavioral medicine : a publication of the Society of Behavioral Medicine. 2013;46(1):81-95.

20. West R, Walia A, Hyder N, Shahab L, Michie S. Behavior change techniques used by the English Stop Smoking Services and their associations with short-term quit outcomes. Nicotine \& tobacco research : official journal of the Society for Research on Nicotine and Tobacco. 2010;12(7):742-7.

21. Moher D, Liberati A, Tetzlaff J, Altman DG. Preferred reporting items for systematic reviews and meta-analyses: the PRISMA statement. Annals of internal medicine. 2009;151(4):264-9.

22. Jadad AR, Moore RA, Carroll D, Jenkinson C, Reynolds DJM, Gavaghan DJ, et al. Assessing the quality of reports of randomized clinical trials: Is blinding necessary? Controlled Clinical Trials. 1996;17(1):1-12.

23. Dienes Z. Bayesian versus orthodox statistics: Which side are you on? Perspectives on Psychological Science. 2011;6(3):274-90.

24. Asfar T, Weg MV, Maziak W, Hammal F, Eissenberg T, Ward KD. Outcomes and adherence in Syria's first smoking cessation trial. American journal of health behavior. 2008;32(2).

25. Girgis S, Adily A, Velasco M-J, Zwar NA, Jalaludin BB, Ward JE. Feasibility, acceptability and impact of a telephone support service initiated in primary medical care to help Arabic smokers quit. Australian journal of primary health. 2011;17(3):274-81.

26. Asfar T, Al Ali R, Rastam S, Maziak W, Ward KD. Behavioral cessation treatment of waterpipe smoking: The first pilot randomized controlled trial. Addictive behaviors. 2014;39(6):1066-74.

27. Ward KD, Asfar T, Al Ali R, Rastam S, Weg MWV, Eissenberg T, et al. Randomized trial of the effectiveness of combined behavioral/pharmacological smoking cessation treatment in Syrian primary care clinics. Addiction. 2013;108(2):394-403.

28. El Sony A, Slama K, Salieh M, Elhaj H, Adam K, Hassan A, et al. Feasibility of brief tobacco cessation advice for tuberculosis patients: a study from Sudan. The International Journal of Tuberculosis and Lung Disease. 2007;11(2):150-5.

29. West R, Marsden J, Humphreys K, Darke S. A revised checklist for writing up research reports. Addiction. 2018.

30. Munafo MR. Promoting reproducibility in addiction research. Addiction.

2017;112(9):1519-20.

31. Grant S, Mayo-Wilson E, Montgomery P, Macdonald G, Michie S, Hopewell S, et al. CONSORT-SPI 2018 Explanation and Elaboration: guidance for reporting social and psychological intervention trials. Trials. 2018;19(1):406.

32. Cahill K, Lindson-Hawley N, Thomas KH, Fanshawe TR, Lancaster T. Nicotine receptor partial agonists for smoking cessation. Cochrane Database Syst Rev. 2016(5):Cd006103.

33. Taylor GMJ, Dalili MN, Semwal M, Civljak M, Sheikh A, Car J. Internet-based interventions for smoking cessation. Cochrane Database Syst Rev. 2017;9:Cd007078. 